www.jmscr.igmpublication.org

Impact Factor (SJIF): 6.379

Index Copernicus Value: 79.54

ISSN (e)-2347-176x ISSN (p) 2455-0450

crossrefDOI: https://dx.doi.org/10.18535/jmscr/v6i8.194

Journal Of Medical Science And Clinical Research

\title{
Comparison of Local Anaesthesia with Sedation to General Anaesthesia in Surgeries of Middle Ear
}

\author{
Authors \\ Dr Sujata Panda ${ }^{1}$, Dr Bimal Panda ${ }^{2 *}$, Dr Sumati Kandi ${ }^{3}$ \\ ${ }^{1}$ Assistant Professor, Dept of Otorhinolaryngology, VIMSAR \\ ${ }^{2}$ Associate Professor, Dept of Anaesthesiology, VIMSAR \\ ${ }^{3}$ Assistant Professor, Dept of Anaesthesiology, VIMSAR \\ *Corresponding Author
}

Dr Bimal Krushna Panda

Associate Professor, Dept of Anaesthesiology, Vir Surendra Sai Institute of Medical Sciences \& Research (VIMSAR), India

\begin{abstract}
Introduction: Middle ear surgeries (MES) can be performed under either general anaesthesia or local anesthesia and sedation and can be well tolerated by the patient with minimal discomfort.

Material \& Methods: Eighty patients of either sex, aged between 20 and 50 years of ASA Grades I and II, undergoing MESs (tympanoplasty and mastoidectomy) under local anaesthesia were included. Patients in Local Anaesthesia group received a bolus dose of injection dexmedetomidine $1 \mu \mathrm{g} / \mathrm{kg} I V$ over 10 min followed by an infusion started at $0.4 \mu \mathrm{g} / \mathrm{kg} / \mathrm{h} \mathrm{IV}$. In patients of General Anaesthesia group inj propofol $1 \mathrm{mg} / \mathrm{kg}$ was given followed by $.1 \mathrm{mg} / \mathrm{kg}$ of vecuronium bromide After 2 minutes pts were put on LMA and maintained with oxygen and nitrous oxide in ratio of $1: 2$ and 0.5 mac of isoflurane throughout the procedure and were switched offon the commencement of skin stitch.

Statistics Hemodynamic data was evaluated using $t$ test for group comparisons. Data not normally distributed was compared using Mann Whitney U test. Categorical data was analyzed using Chi square test. $P$ value less than 0.05 was considered as significant

Result: If patients satisfaction is taken for consideration then general anesthesia technique is preferred over local anesthesia However the middle ear surgery can be performed with any of the methods of anaesthesia.
\end{abstract}

\section{Introduction}

Middle ear surgeries (MES) can be performed under either general anaesthesia or local anesthesia and sedation and can be well tolerated by the patient with minimal discomfort. . Advantages with the local anaesthesia techniques are less bleeding, early recovery, post-operative analgesia, inexpensive and most important one is the ability to test the hearing of the patient intra operatively Commonly used medications for sedation during surgery under local anaesthesia with MAC including opioids, benzodiazepines, propofol and $\alpha 2$ agonists ${ }^{1,2}$. Practicing combination of two agents can provide better patient control and allows the use of smaller doses of each single agent avoiding its undesirable 
effects. Despite these advantages, most of MES are still done under general anesthesia due to special concerns; some are related to patients' anxiety which is augmented in some by their hearing loss, limiting their ability to cooperate. Other concerns are related to surgeon comfortability with the hypotensive general anesthetic techniques, and the fear of sudden patient movement during

Operation $^{2,3}$

\section{Material \& Methods}

After Institutional Ethics Committee approval, written informed consent was taken from all patients who were included in the study. Eighty patients of either sex, aged between 20 and 50 years of ASA Grades I and II, undergoing MESs (tympanoplasty and mastoidectomy) under local anaesthesia were included. Patients with known sensitivity to local anaesthetics, allergy to study drugs, heart disease, renal and hepatic insufficiency, diabetes and hypertension, weighing $<45 \mathrm{~kg}$, obesity (body mass index $>30$ $\mathrm{kg} / \mathrm{m}$ ), pregnant and lactating females were excluded from the study.

Patients were divided randomly into two group, Group A (local anaesthetic) and group B (general anaesthesia with LMA). Patients were placed supine on the operating table with the head turned opposite to the ear to be operated. Routine noninvasive monitoring was applied to all patients with heart rate (HR), peripheral oxygen saturation $(\mathrm{SpO})$, electrocardiogram and non-invasive blood pressure. Intravenous (IV) cannula 20-gauge was secured. Intra operatively all patients received 2 L/min oxygen through nasal catheters. All the patients in both groups were premedicated with IV injection glycopyrrolate $2 \mathrm{mg}$, Pentazocin $.5 \mathrm{mg} / \mathrm{kg}$ midazolam $1 \mathrm{mg} \&$ diclofenac sodium $75 \mathrm{mg} \mathrm{I} / \mathrm{M}$.

Patients in Group A received a bolus dose of injection dexmedetomidine $1 \mu \mathrm{g} / \mathrm{kg}$ IV over 10 min followed by an infusion started at $0.4 \mu \mathrm{g} / \mathrm{kg} / \mathrm{h}$ IV. The level of sedation was assessed using Ramsay Sedation Score (RSS). ${ }^{[10]}$ where the desired sedation level was defined as $\mathrm{RSS} \geq 4$ achieved. Local anesthetic infiltration was performed by the operating surgeon who used lignocaine 2\% with adrenaline 1:200,000 for blocking the tympanic branch of auriculo temporal nerve and great auricular nerve

In patients of Group B inj propofol $1 \mathrm{mg} / \mathrm{kg}$ was given followed by $.1 \mathrm{mg} / \mathrm{kg}$ of vecuronium bromide After 2 minutes pts were put on LMA and maintained with oxygen and nitrous oxide in ratio of $1: 2$ and $0.5 \mathrm{mac}$ of isoflurane throughout the procedure and were switched off on the commencement of skin stitch. Simultaneously, the operating area was prepared and draped. IV paracetamol infusion $1 \mathrm{~g}$ was given as intra operative rescue analgesic and the surgeon used an additional dose of local anaesthetic. If RSS was $<4$, rescue sedation with a bolus of midazolam $0.01 \mathrm{mg} / \mathrm{kg}$ was given.

Haemodynamic parameters were recorded every 10 minutes and any untoward events were noted. RAMSAY Sedation Score ${ }^{6} \quad(1=$ anxious, agitated, restless; $2=$ cooperative, oriented, tranquil; 3 = responds to commands only; $4=$ brisk response to light glabellar tap or loud noise; $5=$ sluggish response to light glabellar tap or loud noise; $6=$ no response) was used for the sedation score.

\section{Statistical Analysis}

Hemodynamic data was evaluated using $t$ test for group comparisons. Data not normally distributed was compared using Mann Whitney $U$ test. Categorical data was analyzed using Chi square test. $P$ value less than 0.05 was considered as significant

\section{Observation}

Table-1 Demographic profile

\begin{tabular}{|l|c|c|}
\hline profile & Group I & Group II \\
\hline Age & 35.7 & 34.3 \\
\hline Sex (M/F) & $26 / 14$ & $24 / 16$ \\
\hline BMI & 23.8 & 24.6 \\
\hline ASA (gr I/II) & $36 / 4$ & $37 / 3$ \\
\hline
\end{tabular}

Both the groups were comparable according to AGE, SEX, BMI \& ASA grading 
Table-2 Baseline Vitals

\begin{tabular}{|l|c|c|}
\hline Baseline vitals & Group I & Group II \\
\hline Heart rate & 88.6 & -86.4 \\
\hline SAP & $117.2(5.17)$ & $115.4(4.11)$ \\
\hline DBP & $79.3(4.27)$ & $78.8(4.35)$ \\
\hline SpO2 & 99 & 99 \\
\hline
\end{tabular}

Both the groups were comparable according to Baseline vitals

Table-3 Type of Surgery

\begin{tabular}{|l|c|c|}
\hline Type of surgery & Group I & Group II \\
\hline tympanoplasey & 25 & 27 \\
\hline mastoidectomy & 15 & 13 \\
\hline
\end{tabular}

Both the groups were comparable according to type of surgery

Table-4 Pulse Rate (PR)

\begin{tabular}{|l|c|c|}
\hline time & Group I & Group II \\
\hline 0 & $88.6(7.6)$ & $86.4(7.94)$ \\
\hline 10 & $92.7(10.51)$ & $93.4(11.26)$ \\
\hline 20 & $92.2(7.28)$ & $92.7(10.51)$ \\
\hline 30 & $90.3(9.11)$ & $90.9(8.69)$ \\
\hline 40 & $88.4(8.35)$ & $89.0(7.03)$ \\
\hline 50 & $87.7(7.98)$ & $88.0(6.74$ \\
\hline 60 & $88.4(7.94$ & $88.4(7.94$ \\
\hline
\end{tabular}

The pre-operative PR was comparable in both group and statistical evaluation shows no significant difference in $\mathrm{PR}(\mathrm{P}=0.69)$.

Table-5 Systolic Blood Pressure (SBP)

\begin{tabular}{|l|c|c|}
\hline time & Group I & Group II \\
\hline 0 & $117.2(5.17$ & $115.4(4.11)$ \\
\hline 10 & $121.1(8.86)$ & $119.7(4.78$ \\
\hline 20 & $127.1(8.19)$ & $129.6(9.35)$ \\
\hline 30 & $119.7(4.78)$ & $121.1(8.86)$ \\
\hline 40 & $118.6(7.51)$ & $117.9(4.47)$ \\
\hline 50 & $117.1(7.03)$ & $116.1(4.23)$ \\
\hline 60 & $115.9(6.76)$ & $115.7(4.99)$ \\
\hline
\end{tabular}

The pre-operative SBP were comparable in both the group and statistical evaluation shows no significant difference in SBP $(\mathrm{P}=0.44)$

Table-6 Diastolic Blood

\begin{tabular}{|l|c|c|}
\hline time & Group I & Group II \\
\hline 0 Base line & $79.3(4.27)$ & $78.8(4.35)$ \\
\hline 10 & $81.3(4.22)$ & $80.7(5.32$ \\
\hline 20 & $82.8(5.52)$ & $82.0(6.84)$ \\
\hline 30 & $80.7(5.32)$ & $81.3(4.22)$ \\
\hline 40 & $80.7(4.56)$ & $80.7(5.32$ \\
\hline 50 & $79.7(4.74)$ & $79.2(5.21)$ \\
\hline 60 & $78.4(4.19)$ & $78.0(4.26$ \\
\hline
\end{tabular}

\section{Pressure (DBP)}

The pre-operative DBP were comparable in both the group and statistical evaluation shows no significant difference in $\mathrm{DBP}(\mathrm{P}=0.31)$.

Table-9 Patient Satisfaction Score

\begin{tabular}{|l|c|c|}
\hline Grade & GroupI (LA) & Group- II (GA) \\
\hline Excellent & 15 & 18 \\
\hline Very Good & 16 & 14 \\
\hline Good & 5 & 6 \\
\hline Average & 4 & 2 \\
\hline Bad & & \\
\hline
\end{tabular}

Patient satisfaction was comparable in both the group. $(\mathrm{P}=0.289)$

\section{Table-10 - Complication}

\begin{tabular}{|l|c|c|}
\hline & Group I & Group II \\
\hline nausea & 4 & 8 \\
\hline vomitting & 1 & 4 \\
\hline drymouth & 4 & 5 \\
\hline hypotension & 4 & 3 \\
\hline Hypertension & 2 & 5 \\
\hline Bradycardia & 3 & 4 \\
\hline Tachycardia & 3 & 6 \\
\hline
\end{tabular}

The incidence of complication were more in general anesthesia group as compared to local anesthesia group

\section{Result}

The local anesthetic technique with sedation had a preference over general anesthesia technique with LMA as it was more preferred by the surgeon and the complication was also fewer though was not statistically significant.

If patient's satisfaction is taken for consideration then general anesthesia technique is preferred over local anesthesia. The middle ear surgery can be performed with any of the methods of anaesthesia.

\section{Discussion}

The patient, surgeon and anesthesiologist may face different set of challenges in Middle- ear surgeries. Sympathetic stimulation and movements of an anxious patient cause increased bleeding and disturb the fine microscopic nature of the surgery which may even lead to graft failure. The advantages of local anesthesia include possibility of testing of hearing intra operatively, having less bleeding, detecting the complications early and a quicker postsurgical emergence ${ }^{3,8}$. The patient needs to be informed prior to infiltration of 
LA that he will be able to feel manipulation of tissues and the noise of instruments, but there will be no pain ${ }^{[3]}$. good patient selection, pre-operative explanation and the use of appropriate sedation are the important factors for local anaesthesia ear procedures to be acceptable to patients. otherwise the intense sensation of noise during the operation (29.6\% of patients) and anxiety (24\%) were the most common discomforts, followed by dizziness (14.8\%), backache (13.9\%), claustrophobia $(9.3 \%)$ and earache $(1.9 \%)^{3 \mathrm{x}}$ A sedative drug should have a quick recovery, and be easy to administer and monitor

Monitored Anaesthesia Care (MAC) is the terminology used for sedation given along with the local anesthesia for short procedures ${ }^{9}$. Over sedation leading to respiratory depression is an important mechanism of patient injuries during $\mathrm{MAC}^{10,12}$. A dose- dependent relationship exists with a sedative induced reduction in ventilator response to hypercarbia. The literature suggests that combining a sedative with an opioid provides effective moderate sedation ${ }^{11}$ Pressor response to Laryngoscopy \& Endotracheal intubation is associated with increase in sympathetic activity. In our study we used LMA instead of ET tube so the haemodynamic parameter and the post operative complication were comparable.

\section{Bibliography}

1. Candiotti KA, Bergese SD, Bokesch PM, Feldman MA, Wisemandle W, Bekker AY MAC Study Group. Monitored anesthesia care with dexmedetomidine: A prospective, randomized, double-blind, multicenter trial. Anesth Analg. 2010;110:47-56. [PubMed]

2. Liang S, Irwin MG. Review of anesthesia for middle ear surgery. Anesthesiol Clin 2010; 28:519-28.

3. Yung MW. Local anaesthesia in middle ear surgery: Survey of patients and surgeons. Clin Otolaryngol Allied Sci 1996; 21:404-8.

4. Sarmento KM, Jr, Tomita S.
Retroauricular tympanoplasty

and tympanomastoidectomy under local anesthesia and sedation. Acta Otolaryngol 2009; 129:726-8.

5. Liang S, Irwin MG. Review of anesthesia for middle ear surgery. Anesthesiol Clin 2010; 28:519-28.

6. Riessen $\mathrm{R}$, Pech $\mathrm{R}$, Tränkle $\mathrm{P}$, Blumenstock G, Haap M. Comparison of the RAMSAY score and the Richmond Agitation Sedation Score for the measurement of sedation depth. Crit Care. 2012;16:326-8.

7. Comparison of Three Drug Combinations for Sedation during Middle Ear Surgeries under Local Anesthesia: A Multicentric Randomized Double Blind Study2 Vikas Kumar, Jyotsna S. Paranjpe, Shishir D. Gosavi, Ruta H. Kulkarni, Rahul S. Gosavi , Tanuja M. Kulkarni JKIMSU, Vol. 4, No. 3, July-September, 2015 ISSN 2231-4261

8. Parikh DA, Kolli SN, Karnik HS, Lele SS, Tendolkar BA. A prospective randomized double-blind study comparing dexmedetomidine vs. combination of midazolam-fentanyl for tympanoplasty surgery under monitored anesthesia care. $J$ Anaesthesiol Clin Pharmacol 2013; 29:173-8

9. Dogan R, Erbek S, Gonencer HH, Erbek HS, Isbilen C, Arslan G. Comparison of local anaesthesia with Dexmedetomidine sedation and general anaesthesia during septoplasty. Eur J Anaesthesiol 2010; 27: 960-4.

10. Bailey PL, Pace NL, Ashburn MA, Moll JW, East KA, Stanley TH. Frequent hypoxemia and apnea aftern sedation with Midazolam and fentanyl. Anesthesiology 1990; 73:826-30.

11. American Society of Anesthesiologists Task Force on Sedation and Analgesia by Non-Anesthesiologists. Practice guidelines for sedation and analgesia by non 
anesthesiologists. Anesthesiology 2002; 96:1004-17

12. Bhananker SM, Posner KL, Cheney FW, Caplan RA, Lee LA, Domino KB. Injury and liability associated with monitored anesthesia care: a closed claims analysis. Anesthesiology 2006; 104:228-34. 